\title{
ARTICLE
}

\section{Use of Mobile Gas Chromatograph Coupled to Mass Spectrometer to Detect Toxic Compounds in Environmental Samples}

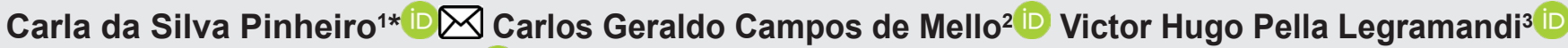 \\ Natalia Fintelman Rodrigues ${ }^{4}$ iD Ana Paula Santiago De Falco ${ }^{5}$ \\ ${ }^{1}$ Centro Tecnológico do Corpo de Fuzileiros Navais. Av. Brasil, 13.476, Parada de Lucas, Rio de Janeiro, 21010- \\ 076, RJ, Brazil \\ ${ }^{2}$ Base de Fuzileiros Navais da Ilha do Governador. Estrada do Quilombo, S/N, Freguesia, Ilha do Governador, Rio \\ de Janeiro, RJ, Brazil \\ ${ }^{3}$ Centro de Defesa Nuclear, Biológica, Química e Radiológica da Marinha do Brasil. Av. Brasil, 13.476, Parada de \\ Lucas, Rio de Janeiro, 21010-076, RJ, Brazil \\ ${ }^{4}$ Fundação Oswaldo Cruz. Av. Brasil, 4365, Manguinhos, Rio de Janeiro, 21040-900, RJ, Brazil \\ 5 Instituto de Pesquisas da Marinha. Rua Ipiru, 02, Cacuia, Rio de Janeiro, 21931-095, RJ, Brazil
}

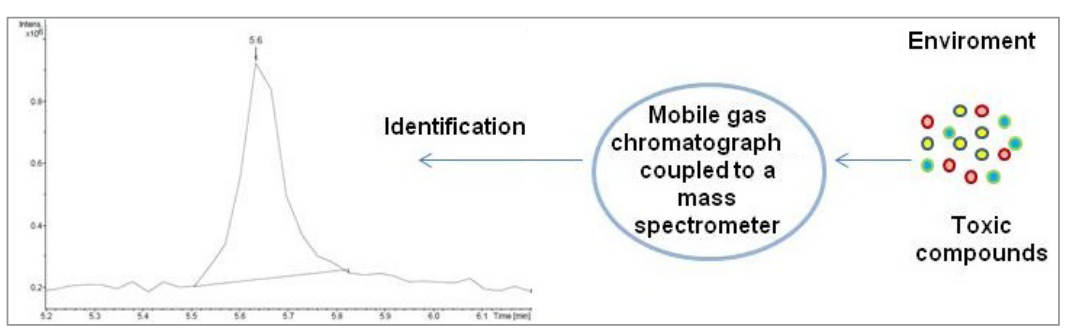

Chemical warfare agents are substances that can be used with military purpose for their ability to cause death, temporary incapacitation or permanent harm in the population. Identification of potentially toxic chemicals used as chemical weapons is of fundamental importance to ensure the physical integrity of the military and civilian population. The objective of this study was to test a method to detect the presence of chemical compounds in environmental samples through direct injection and using Tenax ${ }^{\circledR}$ tube connected to a mobile gas chromatograph coupled to a mass spectrometer (GC-MS) system. Three compounds from a chemical warfare list, used as precursors of chemical weapons, were chosen: 2,6-dimethylphenol, trimethyl phosphate and 1,4-thioxane. These compounds are commercially available for purchase, different from others representatives, which must be synthesized in microscale in a laboratory. The results obtained with the mobile GC-MS system were compared to those obtained with a bench top GC-MS system used in laboratory analysis. Results showed that the use of the mobile GC-MS system was adequate to identify the target compounds, highlighting the importance of its use in field analysis.

Keywords: Chemical weapons, Gas Chromatography, Mass Spectrometry, on-site analysis, mobile gas chromatograph-mass spectrometer.

Cite: Pinheiro, C. S.; de Mello, C. G. C.; Legramandi, V. H. P.; Rodrigues, N. F.; De Falco, A. P. S. Use of Mobile Gas Chromatograph Coupled to Mass Spectrometer to Detect Toxic Compounds in Environmental Samples. Braz. J. Anal. Chem., 2020, 7 (27). doi: http://dx.doi.org/10.30744/brjac.2179-3425.AR-44-2019 


\section{INTRODUCTION}

According to the "Convention on the Prohibition of the Development, Production, Stockpiling and Use of Chemical Weapons and Their Destruction", toxic chemical compounds are those which may lead to death, temporary incapacity or permanent risk to humans or animals, regardless of their production method [1]. Since ancient times, chemical agents have been used as tools of warfare, however, the advent of the chemical industry in the second half of the nineteenth century has made its use technically feasible as weapons with great potential for mass destruction [2]. In the military context they cause more casualties than conventional weapons. A major difference between conventional and chemical weapons is the fact that chemical weapons target general population, not just military personnel on a battlefield. As such, it ceases to be an essentially military concern and becomes a social and economic concern.

Numerous techniques can be used to identify highly toxic chemical compounds with potential terrorist use. Among them, the chromatography, a physicochemical method of separating the components of a mixture, realized through the distribution of these components between two phases: one stationary and the other mobile [3]. Specifically, in the case of chemical warfare compounds, gas chromatography coupled to mass spectrometry (GC-MS) technique is the most widely used. The gas chromatography segregates the components of a mixture, while the mass spectrometry provides the structural information on each of them [4]. GC-MS analysis can also generate quantitative data when known concentration patterns are used with the unknown sample.

$E^{2} \mathrm{M}$ equipment $\left(\right.$ Bruker $\left.^{\circledR}\right)$ used in this study can be defined as a quadrupole mass spectrometer system aimed to be used for on-site analysis. Because of that it was developed to be a compact and robust system capable of be used statically or mounted on a vehicle. The system's greatest advantage is its sensitivity, since it is able of detecting compounds in concentrations on the order of parts per million (ppm). A feature of this system is the use of atmospheric air from the environment $(78 \%$ nitrogen, $21 \%$ oxygen, $0.93 \%$ argon and $0.039 \%$ carbon dioxide) as a mobile phase, which makes the transport of mobile phase cylinders unnecessary [5]. On the other hand, the use of atmospheric air as a mobile phase would be a disadvantage in the analysis of easily oxidizable compounds. This made it necessary to use an inert gas as a mobile phase.

$\mathrm{E}^{2} \mathrm{M}$ is a system that can be used for direct injection of samples or coupled to Tenax ${ }^{\circledR}$ tubes from which the retained analytes can be desorbed and introduced into the chromatographic column. The first technique used for standard samples identification was based on direct injection in the $\mathrm{E}^{2} \mathrm{M}$ system. Injectors are used to introduce the sample into the GC column. This direct injection has a good accuracy, precision and can be used with a wide range of analyte concentrations. A small amount of liquid (microliters) is injected through a septum (using a special microliter syringe) into the hot GC injector. It is kept hot by a relatively large, metal heater block that is thermostatically controlled. The sample is immediately vaporized and a pressurized, inert, carrier gas - which is continually flowing from a gas regulator through the injector and into the GC column - sweeps the gaseous sample, solvent, analyte into the column. In this system, gaseous sample is transferred into the column, increasing separation capacity and compounds identification. The second technique used for standard samples identification was based on thermal desorption with Tenax ${ }^{\circledR}$ tube, during analysis of environmental samples. The use of the Tenax ${ }^{\circledR}$ tube consists of a desorption method in which volatile compounds are adsorbed in a Tenax ${ }^{\circledR}$ tube matrix. Thermal desorption sample tubes can be used either empty, for desorbing volatiles from materials or packed with sorbent for retaining vapour organic phase. Tenax ${ }^{\circledast}$ is an inert sorbent used for hydrophobic samples. Considering this, the main purpose of this study was to test a methodology for the detection of chemical compounds using a mobile equipment $\left(\right.$ Bruker $\left.^{\circledR}\right)$ simulating on-site analysis. For this purpose, samples were analyzed by GC injector and Tenax ${ }^{\circledR}$ cartridge and then compared to analysis made with a bench equipment (Agilent $\left.{ }^{\circledR}\right)$. Development and validation of this methodology will make it possible to obtain a robust and reliable analysis of sample contaminated with toxic compounds, using a mobile equipment, resulting in a faster response in contaminated areas. 


\section{MATERIALS AND METHODS \\ Equipment}

For this study, a Bruker ${ }^{\circledR}$ gas chromatograph coupled to mass spectrometer (GC-MS) system, model $E^{2} \mathrm{M}$, was used. Such equipment was developed for analysis of samples in the field, and can be transported. For this, it is a robust equipment.

\section{Reagents}

Three analytical standards were used: 2,6-dimethylphenol (Merck, \#S4766472), trimethyl phosphate (Sigma-Aldrich, \#MKBS5276V), 1,4-thioxane (Sigma-Aldrich, \#MKBL9089V). The solvent used in the preparation of samples was methanol (Vetec, \#DCBD2408V). For linear retention index (LRI) calculated based on alkane series, a saturated alkanes standard (C7-C30 from Sigma, \#LC13543V) was used.

\section{Sample preparation}

For both direct injection and Tenax ${ }^{\circledR}$ tube assays, the chemical compounds were diluted in methanol. In direct injection, solutions were injected in the GC-MS systems using a syringe. For Tenax ${ }^{\circledR}$ tube, after sample preparation, tubes were disposed near the opened vial with the solution and air sample pumped ten times with an Accuro manual pump, Dräger ${ }^{\circledR}$. Sample tubes of $100 \mathrm{~mL}$ were used.

\section{Solutions}

Solutions were prepared using methanol as solvent, following the description in Table I.

Table I. Concentrations of work solutions of reference chemicals used for direct analysis (mobile or bench top GCMS systems) and Tenax ${ }^{\circledR}$ tube

\begin{tabular}{|c|c|c|c|}
\hline \multirow[b]{2}{*}{ Reference chemical } & \multicolumn{3}{|c|}{ Work solution concentration (ppm) } \\
\hline & Direct Analyses & Bench top & Tenax $^{\circledR}$ tube \\
\hline 2,6-dimethylphenol & $20 ; 50 ; 75 ; 100 ; 125 ; 150 ; 200$ & $10 ; 15 ; 20 ; 30 ; 40$ & $50 ; 75 ; 100 ; 150 ; 200$ \\
\hline Trimethylphosphate & $\begin{array}{c}300 ; 500 ; 750 ; 1000 ; 1500 \\
2000 ; 3000\end{array}$ & $10 ; 15 ; 20 ; 30 ; 40$ & $500 ; 750 ; 1000 ; 1500 ; 3000$ \\
\hline 1,4-thioxane & $\begin{array}{c}50 ; 100 ; 150 ; 200 ; 250 ; 300 ; \\
350\end{array}$ & $2.5 ; 5 ; 7.5 ; 10 ; 12.5$ & $50 ; 100 ; 150 ; 300 ; 350$ \\
\hline $\begin{array}{l}\text { Compound mixture } \\
\text { (2,6-dimethylphenol; } \\
\text { Trimethylphosphate; } \\
\text { 1,4-thioxane) }\end{array}$ & 1000 & - & - \\
\hline
\end{tabular}

\section{Chromatographic conditions}

The chromatographic column used for direct injection in the mobile GC (E'M-Bruker $\left.{ }^{\circledR}\right)$ was a MXT-5 column (Restek) of $12 \mathrm{~m}$, internal diameter of $0.32 \mathrm{~mm}$ and film thickness $0.5 \mu \mathrm{m}$; the injector temperature was $240^{\circ} \mathrm{C}$; the initial oven temperature was $45^{\circ} \mathrm{C}$ held for 1 minute, followed by an increase of $15^{\circ} \mathrm{C}$ per minute up to $160^{\circ} \mathrm{C}$ held for 1 minute and, finally, an increase of $35^{\circ} \mathrm{C}$ per minute up to $240{ }^{\circ} \mathrm{C}$ held for 3 minutes. The mobile phase was atmospheric air with flow rate of $1.5 \mathrm{~mL} / \mathrm{min}$.

In direct injection in the bench GC (Agilent ${ }^{\circledR}$ ), a DB5-MS column of $30 \mathrm{~m}$, internal diameter of $0.25 \mathrm{~mm}$ and film thickness $0.25 \mu \mathrm{m}$ was used; the injector temperature was $250{ }^{\circ} \mathrm{C}$; the initial oven temperature was $40^{\circ} \mathrm{C}$ held for 1 minute, followed by an increase of $10^{\circ} \mathrm{C}$ per minute to $300^{\circ} \mathrm{C}$ held for 10 minute. The mobile phase was ultra-pure helium with flow rate of $1 \mathrm{~mL} / \mathrm{min}$.

For Tenax ${ }^{\circledR}$ tube, the chromatographic column used was a MXT-5 column of $12 \mathrm{~m}$, internal diameter of 
$0.32 \mathrm{~mm}$ and film thickness $0.5 \mu \mathrm{m}$; the injector temperature was $240{ }^{\circ} \mathrm{C}$; the initial oven temperature was $45^{\circ} \mathrm{C}$ for 1 minute, followed by an increase of $15^{\circ} \mathrm{C}$ per minute until $160^{\circ} \mathrm{C}$ held for 1 minute, and finally an increase of $35^{\circ} \mathrm{C}$ per minute up to $240^{\circ} \mathrm{C}$, held for 3 minutes. The mobile phase was atmospheric air with flow rate of $1.5 \mathrm{~mL} / \mathrm{min}$.

\section{Data analysis}

The mass spectra were obtained in the range of $15-600 \mathrm{~m} / \mathrm{z}$. The identification of chemical agents was performed using the OPCW Central Analytical Database library and the comparison was performed by the AMDIS software.

Calibration curves were constructed according to the ANVISA's Resolution RDC 166/2017 [6], which defines that 3 curves are obtained in graphic signal intensity as a function of the concentration, and at least 5 different concentrations should be used. For each analytical standard, 5 concentrations were analyzed and plotted on a graph as described. Then, the equation of the line and $r^{2}$ were determined with the aid of the LibreOffice Calc application. In order to prove linearity, the value of $r^{2}$ must be greater than 0.99 [6]. Also, according to the ANVISA's Resolution, the calculation of the limit of detection (LD) is given by Equation 1:

$$
\mathrm{LD}=\frac{3.3 \times \sigma}{\mathrm{IC}} \quad \text { Equation } 1
$$

where $\sigma$ is the standard deviation of the intercept with the $Y$ axis of at least 3 calibration curves constructed with concentrations close to the supposed limit of detection and IC is the slope of the line obtained in the calibration curve.

To calculate the LRI based on saturated alkanes standard (C7-C30) Equation 2 was used:

$$
\mathrm{RI}=(\mathrm{N} \times 100)+\left[2 \times 100\left(\frac{\mathrm{t}_{\mathrm{c}}-\mathrm{t}_{\mathrm{n}}}{\mathrm{t}_{\mathrm{n}+2}-\mathrm{t}_{\mathrm{n}}}\right)\right] \quad \text { Equation } 2
$$

where $\mathrm{RI}$ is retention index; $\mathrm{N}$ is the number of carbons of the previous hydrocarbon; $\mathrm{t}_{\mathrm{c}}$ is the retention time of the compound of interest; $t_{n+2}$ is the retention time of the posterior hydrocarbon; $t_{n}$ is the retention time of the previous hydrocarbon; $n+2$ is used to calculate retention index, considering that OCAD library data were obtained using saturated alkanes standard with even carbon numbers so, data must consider only even alkanes with even carbon number [7].

The alkane series standard was injected $(1 \mu \mathrm{L})$ into the GC-MS system operating under the conditions previously described, and their respective retention times were used as an external reference standard for calculating the RI, together with the retention times of each compound of interest. Otherwise, it represents an important tool of identification and differentiation of isomer compounds.

\section{RESULTS AND DISCUSSION}

Analysis and determination of detection limit for 3 toxic compounds (2,6-dimethylphenol, 1,4-thioxane and trimethyl phosphate) was done using GC injector in E2M GC-MS equipment. Such procedure was tested for each compound of interest in order to determine the limit of detection individually. Only this way would be possible to determine limitations and capabilities of this equipment and method. Otherwise, limit of detection could be used as an important tool for analysts and technicians that operate mobile laboratories or first responder teams against accidents or attacks involving chemical warfare agents or toxic industrial compounds.

For this step, three analytical standards were used: 2,6-dimethylphenol, trimethyl phosphate and 1,4-thioxane. For each compound it was verified the retention time and mass spectra, as well as a calibration curve to study linearity and limit of detection according to ANVISA RDC 166/2017 [6]. 
The analysis of 2,6-dimethylphenol allowed to define total ion chromatogram and its retention time as 5.6 minutes (Figure 1A), as well as to determine the mass spectrum obtained in our experiments (Figure 1B). This spectrum was compared to the OCAD spectrum (Figure 1C), correctly identifying the chemical agent analyzed.

For limit of detection determination, a calibration curves mean was performed, achieving linearity requisition. The standard deviation of the points that intercept the $Y$ axis was obtained using the software LibreOffice Calc, and its value was 10907,51 . Substituting this value into the limit of detection equation (Equation 1), the calculated limit of detection for 2,6-dimethylphenol was $7.15 \mathrm{ppm}$.

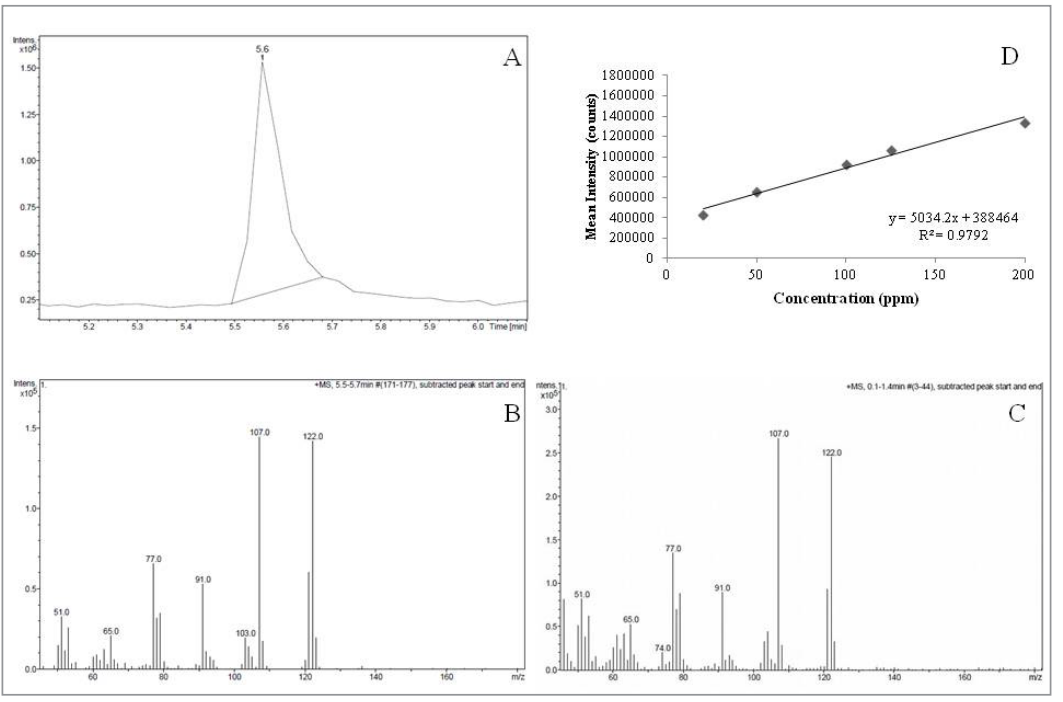

Figure 1. A: Total ion chromatogram obtained in the 2,6-dimethylphenol analysis; $B, C$ : Mass spectra obtained by the validated 2,6-dimethylphenol method and the OCAD library; D: Calibration curves mean. Concentration: 200 ppm.

After this limit of detection determination, a saturated alkanes standard (C7-C30) was used to verify the performance of the GC-MS system and calculate the retention index (RI) of each compound in the sample. Calculated RI values were compared with values found in the literature for columns of the same polarity. The standard of these alkanes was injected $(1 \mu \mathrm{L})$ into the GC-MS system operating under the conditions previously described, and their respective retention times were used as an external reference standard for the calculation of the RI, together with the retention times of each compound of interest [8].

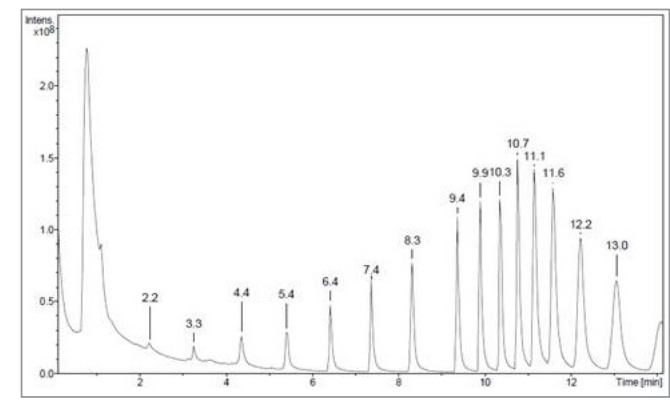

Figure 2. Total ion chromatogram obtained in the saturated alkanes standard (C7-C30) analysis.

As it can be observed, 2,6-dimethylphenol RT (OCAD libray) is 1.112, while LRI calculated, using Equation 2, was 1.120, a difference lower than 20 units between RI library and LRI calculated (D). It indicates a good performing of GC-MS system using MXT-5 column [8]. 
For the second compound analyzed, 1,4-thioxane, the retention time obtained was 3.2 minutes and its mass spectrum, both obtained and that one of the library, can be observed. As it can be verified in OCAD library, 1,4 thioxane RI is 897,743 while LRI calculated was 882 , indicating a good performance of GCMS system using the MXT-5 column. Following the limit of detection analyses, calibration curves were performed for 1,4-thioxane, as well as the curve obtained with the mean intensities, which can be observed in Figure 3.

In this case, the method meets the linearity criterion considering the mean of curve of the intensities. The standard deviation obtained with the measures of the points of intersection with the $Y$ axis was 8223 . Substituting this value into the equation for the calculation of the limit of detection results in $4.61 \mathrm{ppm}$.

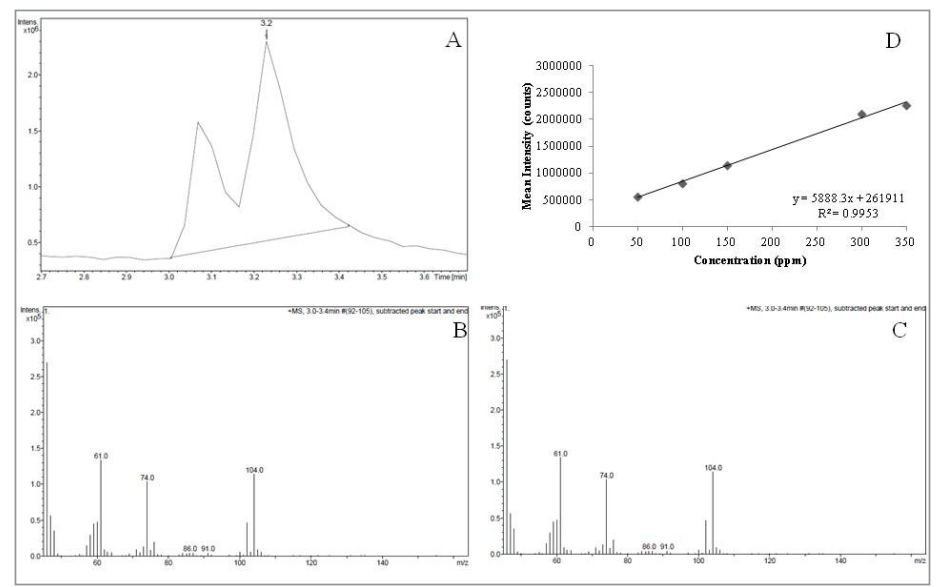

Figure 3. A: Total ion chromatogram obtained in 1,4-thioxane analysis; B,C: Mass spectra obtained by the validated 1,4-thioxane method and the OCAD library; D: Calibration curves mean. Concentration: 350 ppm.

Analysis of the third compound, trimethyl phosphate solutions, showed retention time 4.1 minutes. The ion chromatogram, mass spectra obtained and the OCAD library and mean intensity calibration curve are shown in Figure 4.

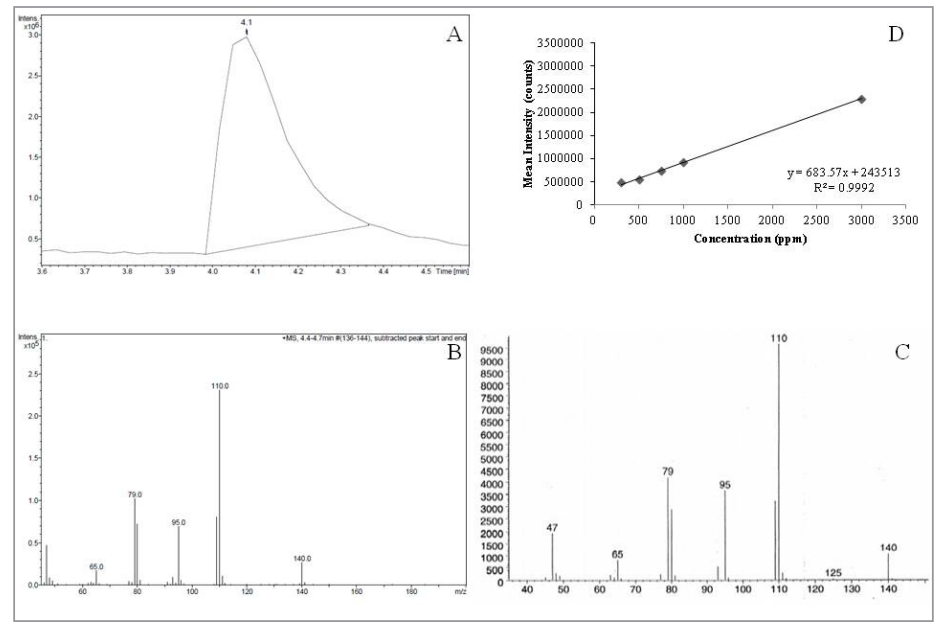

Figure 4. A: Total ion chromatogram obtained in trimethyl phosphate analysis;

$B, C$ : Mass spectra obtained by the validated method and the OCAD library; D: Calibration curves mean. Concentration: 3000 ppm. 
As it can be observed in OCAD library, trimethyl phosphate RI is 946,1606 while LRI calculated was 972, indicating that for experimental condition used, it was not possible achieve a good chromatographic performance. The limit of detection was 49,19 ppm.

To check the performance of the mobile GC-MS when compared to a bench top equipment we decided to compare the obtained limits of detection with those that could be obtained on the Agilent equipment. We used the same reference chemicals and prepared solutions with the same solvent, but in different concentrations. Three calibration curves were obtained and they were used to obtain a calibration curve with the average of the intensities. Linearity and limit of detection were determined according to ANVISA RDC 166/2017 [6]. The analytical conditions are described in the experimental item.

The analysis of 2,6-dimethylphenol allowed to define its retention time as 10.232 minutes, according to Figure 5, as well as to define the mass spectrum obtained in our experiments. This spectrum was compared to the OCAD spectrum, correctly identifying the chemical agent analyzed (Figure 5).

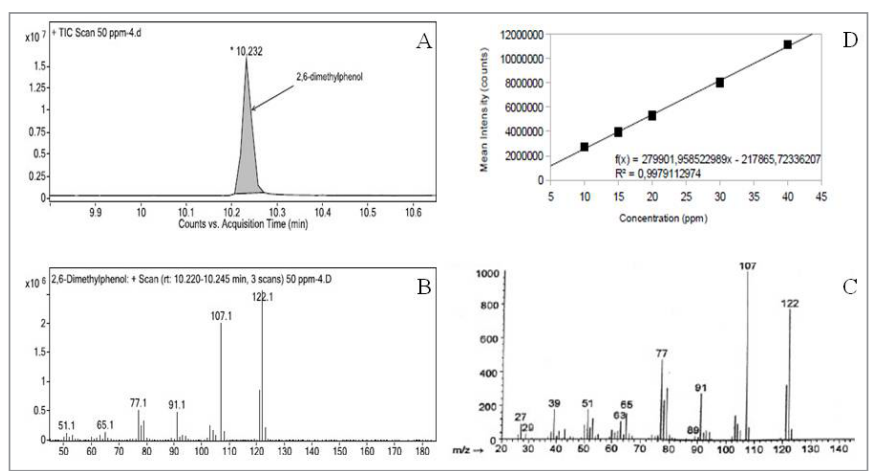

Figure 5. A: Total ion chromatogram obtained in the 2,6-dimethylphenol analysis; B,C: Mass spectra obtained by the validated 2,6-dimethylphenol method and the OCAD library; D: Calibration curves mean. Assay using a bench top equipment.

The standard deviation of the points that intercept the $Y$ axis was obtained using the software LibreOffice Calc, and its value was 120263,35. Substituting this value into the limit of detection equation (Equation 1), the calculated limit of detection for 2,6-dimethylphenol was $1.41 \mathrm{ppm}$. As expected, the bench top instrument is more sensitive than the mobile one. However, difference between them is not so significant, considering that they are in the same order of magnitude.

For the second compound analyzed, 1,4-thioxane, the retention time obtained was 6.86 minutes. Figure 6 shows its mass spectrum, both obtained and that of the library, and the calibration curves performed following the limit of detection analysis, as well as the curve obtained with the mean intensities.

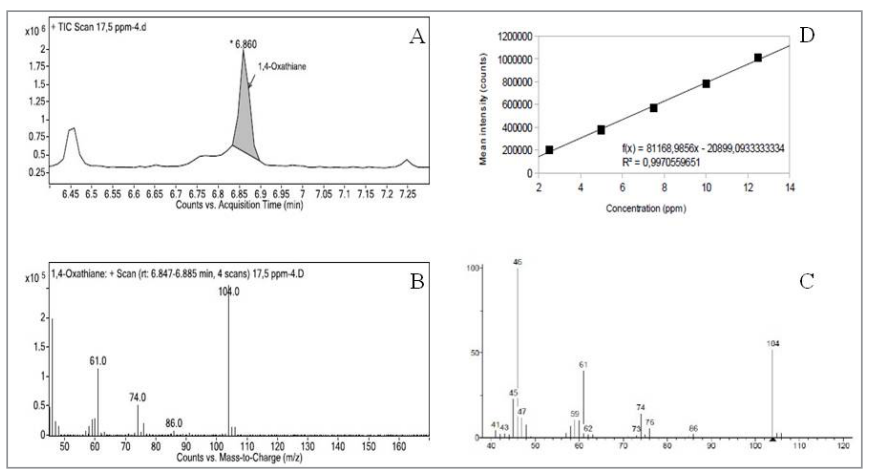

Figure 6. A: Total ion chromatogram obtained in the 1,4-thioxane analysis; B,C: Mass spectra obtained by the validated 1,4-thioxane method and the OCAD library;

D: Calibration curves mean. Assay using a bench top equipment. 
In this case, the method meets the linearity criterion in all obtained curves. The standard deviation obtained with the measures of the points of intersection with the $Y$ axis was 29491,52. Substituting this value into the equation for the calculation of the limit of detection results in $1.20 \mathrm{ppm}$.

The third compound analyzed was trimethyl phosphate and its retention time was 7.493 minutes, according to Figure 7, as well as to define the mass spectrum obtained in our experiments. This spectrum was compared to the OCAD spectrum, correctly identifying the analyzed chemical agent.

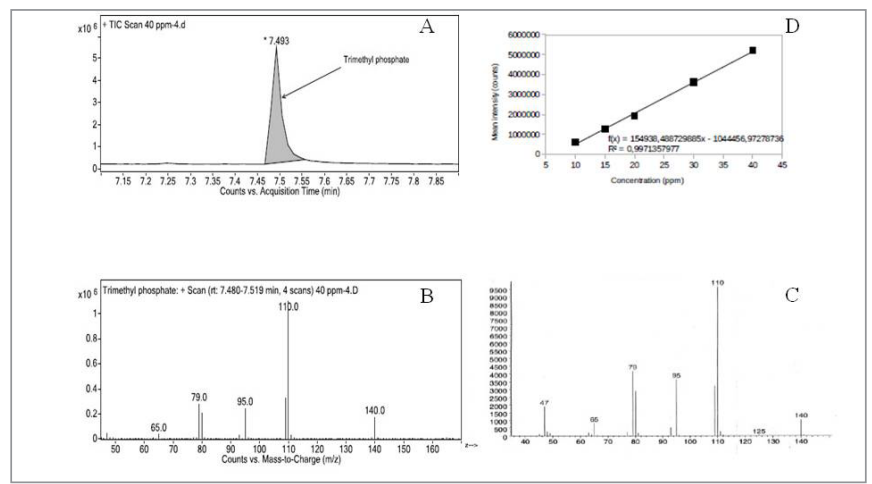

Figure 7. A: Total ion chromatogram obtained in the trimethyl phosphate analysis; B,C: Mass spectra obtained by the validated trimethyl phosphate method and the OCAD library; D: Calibration curves mean. Assay using bench top equipment.

In mean intensity curve the linearity criterion was met, including the curve with the average of the intensities. The standard deviation of the points that intersect the $Y$ axis was 239491,59 . Thus, the new limit of detection was $5.10 \mathrm{ppm}$. As expected, for all three compounds the bench top equipment showed lower limit of detection than the mobile equipment, but the difference between them is not so significant considering that they are all in the same order of magnitude.

Although the difference between both limit of detection in the bench top GC-MS and in the mobile equipment, linearity is better in the first one. Besides that, the repetition of the results is also better in the Agilent equipment.

These parameters could suggest that the $E^{2} \mathrm{M}$ is not as good as the Agilent equipment. However, considering that we aimed a qualitative method to be used in the place where an accident or terrorist attack occurred, we could consider that our result is adequate to on-site analysis, that will be after confirmed by a forensic laboratory.

Last part of this study was evaluating limit of detection using Tenax ${ }^{\circledR}$ tube, a cartridge which adsorves environmental toxic molecules in air samples. Analysis and determination of limit of detection for three toxic compounds (2,6-dimethylphenol, 1,4-thioxane and trimethyl phosphate) were performed. Only this way would be possible to determine limitations and capabilities of this equipment and method using sample in a vapor state. For this step of the project, three analytical standards were used: 2,6- dimethylphenol, trimethyl phosphate and 1,4-thioxane.

The main advantage of this method is that it is not necessary to prepare a solution or use a solvent to extract the analytes from the matrix, considering that we can take the molecules directly from the air. Also, molecules will be concentrated in the Tenax ${ }^{\circledR}$ tube until saturation of the powder, so even if the concentration of the analyte is low, it can be concentrated before the analysis.

As a disadvantage, we can consider that it would be possible to analyze just volatile molecules, but, considering the CWA, most of them could be analyzed by this method, considering that they will be volatile at least partially.

The analysis of 2,6-dimethylphenol allowed to define its retention time as 5.6 minutes, according to Figure 8, as well as to define the mass spectrum obtained in our experiments. This spectrum was compared to the OCAD spectrum, correctly identifying the analyzed chemical agent. Following limit of 
detection analysis, three calibration curves were performed for 2,6-dimethylphenol, as well as the curve obtained with the mean intensities, which can be observed in Figure 8.

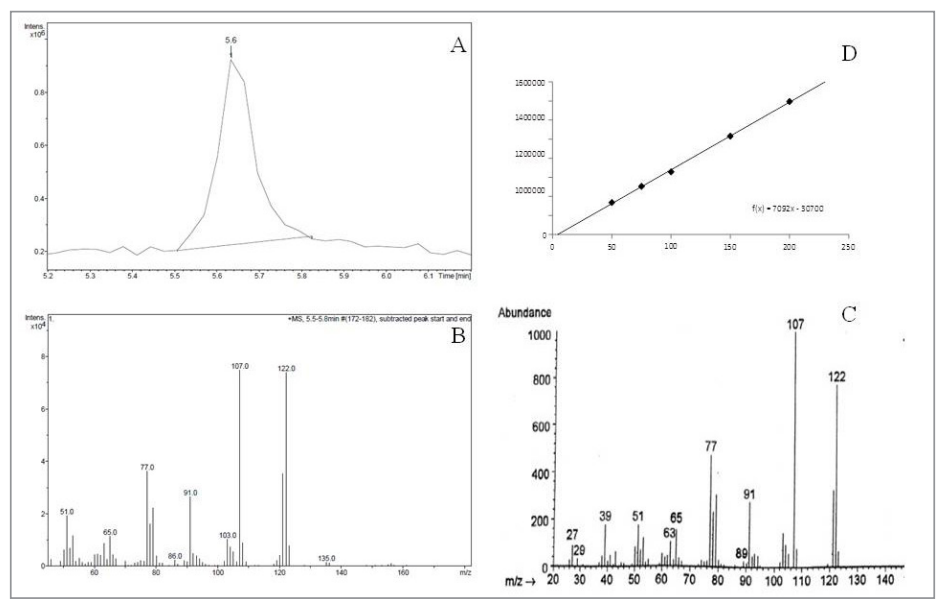

Figure 8. A: Total ion chromatogram obtained in the 2,6-dimethylphenol analysis; B,C: Mass spectra obtained by the validated 2,6-dimethylphenol method and the OCAD library;

D: Calibration curves mean. Assay using Tenax ${ }^{\circledR}$ tube.

As can be observed in Figure 8, the linearity criterion was achieved using mean intensities. In view of this, the limit of detection was calculated using Equation 1 and the results were tested by analysing a solution with concentration near the calculated limit of detection. Considering that the standard deviation of the points that intercept the $Y$ axis was obtained using the software LibreOffice Calc, and its value was 50320.06 , limit of detection calculated is $23,41 \mathrm{ppm}$, a lower concentration (20 ppm) was tested. However, in this concentration, it was not possible to achieve a match greater than 80 (data not shown).

For the second compound analyzed, 1,4-thioxane, the retention time obtained was 3.1 minutes and its mass spectrum, both obtained and that of the library, can be observed in Figure 9. Following limit of detection analysis, three calibration curves were performed for 1,4-thioxane, as well as the curve obtained with the mean intensities, which can be observed in Figure 9.

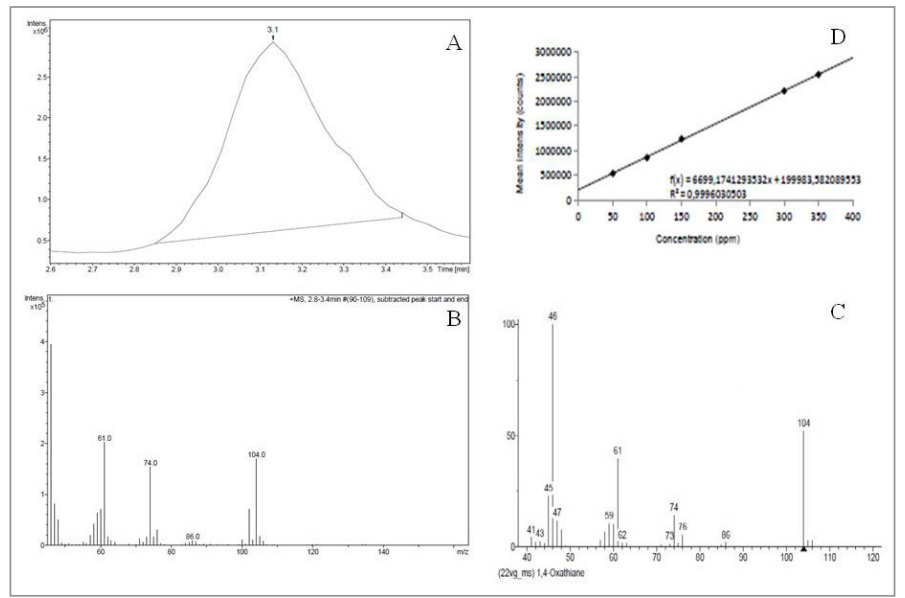

Figure 9. A: Total ion chromatogram obtained in the 1,4-thioxane analysis; B,C: Mass spectra obtained by the validated 1,4-thioxane method and the OCAD library; D: Calibration curves mean. Assay using Tenax ${ }^{\circledR}$ tube. 
The mean intensities resulted in a linear curve. Also, the $r^{2}$ for all of them, are much better than for the 2,6-dimethylphenol. The standard deviation of the points that intercept the $Y$ axis was obtained using the software LibreOffice Calc, and its value was 9005,85. Substituting this value into the limit of detection equation (Equation 1), the calculated limit of detection for I,4-thioxane was 4,43 ppm.

The third compound analyzed was trimethyl phosphate and its retention time was 4.5 minutes, according to Figure 10, as well as to define the mass spectrum obtained in our experiments. This spectrum was compared to the OCAD spectrum, correctly identifying the analyzed chemical agent (Figure 10). It was not possible to obtain calibration curve for this compound.

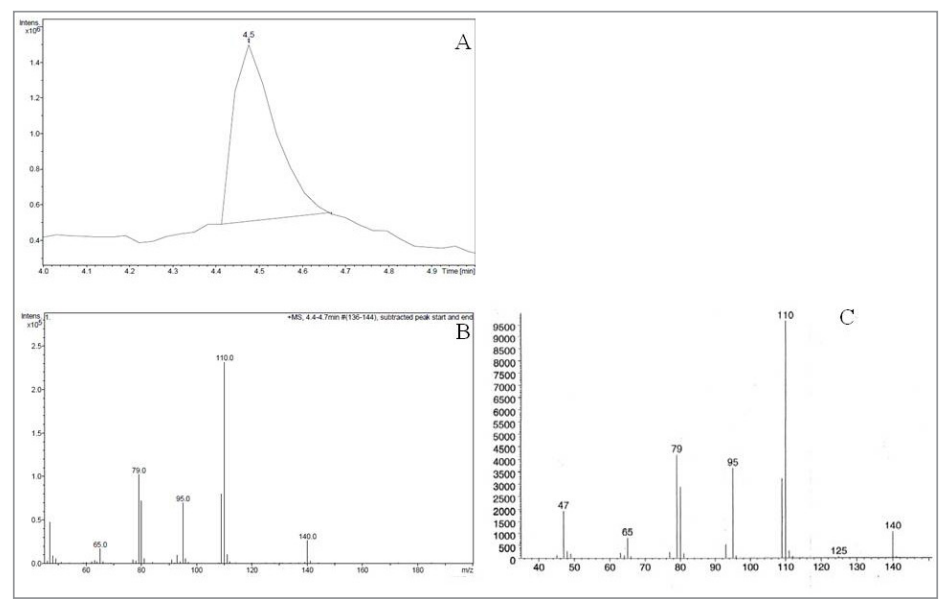

Figure 10. A: Total ion chromatogram obtained in trimethyl phosphate analysis; B,C: Mass spectra obtained by the validated, trimethyl phosphate method and the OCAD library; Assay using Tenax ${ }^{\circledR}$ tube.

Following limit of detection analysis, we tried to obtain three calibration curves for trimethyl phosphate, but that was not possible even for the mean intensities. Because of that, we could not calculate the limit of detection for trimethyl phosphate using the Tenax ${ }^{\circledR}$ tube.

Single stage thermal desorption - i.e., direct transfer of the analytes from the heated sample tube to the analytical system - produces broad component bands that are only compatible with packed column chromatography. A key advantage of tube monitoring methods is that many of the sorbents available do not retain water during the sampling process, thus preventing any risk of water interfering with the subsequent chromatographic analysis, especially in a GC-MS [9].

Using this methodology, it was possible to determine the minimum concentration detected in mobile GC-MS E²M Bruker ${ }^{\circledR}$, but not for the trimethyl phosphate, whose linearity criterion was not met. Despite of the identification, we were not able to determine a linear curve using Tenax tube ${ }^{\circledR}$ for sample desorption. Probably, it was due to a small amount of vapor sample collected with the pump for each compound, although 10 pumping were carried out. It is worth noting that perhaps the most popular tube packing material - Tenax ${ }^{\circledR}$ TA - is a very weak adsorbent, suitable only for components less volatile than benzene.

Although it was not possible to determine a limit of detection using the mobile GC-MS E²M Bruker ${ }^{\circledR}$, sample adsorption using Tenax ${ }^{\circledR}$ tube give enormous advantages over solvent extraction in terms of reusable tubes and environmental acceptability. Thermal desorption (TD) could replace solvent extraction for almost all air monitoring applications. A possibility to improve results is to use an automatic pump that would collect enough air volume until chemicals are concentrated in the Tenax ${ }^{\circledR}$ tube and then analyzed by GC-MS. 


\section{CONCLUSIONS}

Gas chromatography combined with mass spectrometry (GC-MS) provides analytical information that is definitive for many types of samples containing organic analytes. Over the last decade, field-portable GC-MS systems have played a major role in key environmental as well as forensic applications [10].

Field analysis requirements typically include the need for rapid assessment of the volatile organic compounds (VOCs) present, because these compounds can be inhaled and, therefore, represent the highest immediate health danger. The VOCs that represent the most credible and immediate danger to individuals include many industrial compounds, such as phosgene or cyanogen chloride, as well as chemical warfare agents (CWAs), such as volatile nerve agent Sarin [10].

With all studied analytical method, it was possible to identify the chemical agents in relatively low concentrations, especially considering the lethal doses of each one, which are several orders of magnitude above the determined limits of detection.

Although we did not meet the linearity criterion in all cases, it is important to highlight that the objective was not to validate a quantitative method of analysis, but rather a qualitative method to identify such compounds in field analysis that will be later confirmed by forensic laboratories.

For these reasons, the proposed methods were considered adequate for their purpose, contributing to the qualification of the team and to the reliability of the results obtained by an equipment for its use in field analyses, especially those involving accidents and the need of care for victims.

\section{Acknowledgment}

The authors thank the Organizations for the Prohibition of Chemical Weapons (OPCW) for financial support for this study.

\section{REFERENCES}

1. Organization for the Prohibition of Chemical Weapons (OPCW). Convention on the Prohibition of the Development, Production, Stockpiling and Use of Chemical Weapons and on their Destruction, 1997. https://www.opcw.org/chemical-weapons-convention [Acessed on March 2020].

2. Silva, G. R.; Borges Junior, I.; Figueroa-Villas, J. D.; Castro, A. T. Quim. Nova, 2012, 35 (10), pp 2083-2091 (http://dx.doi.org/10.1590/S0100-40422012001000033).

3. Penteado, J. C. P.; Magalhães, D.; Masini, J. C.; Quim. Nova, 2008, 31 (8), pp 1-4. (http://dx.doi. org/10.1590/S0100-40422008000800047).

4. Furtado, M. A.; Tira-Picos, V. Boletim da Sociedade Portuguesa de Química, 2014, 135, pp $25-32$.

5. DellaSala, D. A. Encyclopedia of the Anthropocene, 2018, 2, pp 387-389 (https://doi.org/10.1016/ B978-0-12-809665-9.05872-9).

6. Diário Oficial da União, Ministério da Saúde do Brasil, Agência Nacional de Vigilância Sanitária (ANVISA), Diretoria Colegiada, Resolução RDC No 166, de 24 de julho de 2017. Dispõe sobre a validação de métodos analíticos e dá outras providências. Publicado em: 25/07/2017, Edição: 141, Seção: 1, Página 87, Brasília, DF, 2017. http://www.in.gov.br/materia/-/asset_publisher/ Kujrw0TZC2Mb/content/id/19194581/do1-2017-07-25-resolucao-rdc-n-166-de-24-de-julhode-2017-19194412 [Acessed on March 2020].

7. Organization for the Prohibition of Chemical Weapons (OPCW) Central Analytical Database (OCAD), 2019.

8. Viegas, M. C.; Bassoli, D. G. Quim. Nova, 2007, 30 (8), pp 2031-2034 (http://dx.doi.org/10.1590/ S0100-40422007000800040).

9. Woolfenden, E. J. Air Waste Manage. Assoc., 1997, 47, pp 20-36 (https://doi.org/10.1080/10473289. 1997.10464411).

10. Eckenrode, B. A. J. Am. Soc. Mass Spectrom., 2001, 12 (6), pp 683-693 (https://doi.org/10.1016/ S1044-0305(01)00251-3). 